\title{
Remote monitoring of operational parameters for the cane honey production process
}

\author{
Monitoreo remoto de los parámetros operacionales \\ para el proceso de producción de miel de caña
}

\section{Octavio Edelberto Guijarro Rubio", Víctor Rodrigo Cerda Mejía ${ }^{* *}$ Isnel Benítez Cortés ${ }^{\star \star *}$,

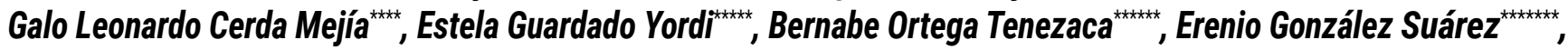 Amaury Pérez Martínez}

(Recibido el 04-06-2021. Aprobado el 30-06-2021. Publicado 12-07-2021)

Estilo de citación de artículo:

0. E. Guijarro Rubio, V. R. Cerda Mejia, I. Benitez Cortés, G. L. Cerda Mejía, E. Guardado Yordi, B. Ortega Tenezaca, E. Gonzales Suárez and A. Perez Martínez,

"Remote monitoring of operational: parameters for the cane honey production process", Lámpsakos, no. 25, pp. 59-69, 2021. D0I: 10.21501/21454086.3991

\begin{abstract}
:
A local data acquisition, processing, and storage system were implemented through an open-source micro-controlled development card. To continuously measure the variables of the cane honey production process, it was performed using five temperature sensors, a $\mathrm{pH}$ sensor, and a level sensor. Each sensor was associated with a component set with its respective upper and lower reference values during the processing of a batch of product. The main objective was to determine the effectiveness of using sensors and wireless communication technology to monitor operational parameters in real-time. In general, the recorded temperature, $\mathrm{pH}$, and level data obtained from sensors corresponded closely to the changes that occurred in the process. The wireless communication nodes developed successfully measured and monitored the temperature, $\mathrm{pH}$, and level readings in real-time. The study also found that the sensors' temperature, $\mathrm{pH}$, and level readings began to standardize more closely within the upper and lower limits. Furthermore, operational parameters could be reasonably predicted by applying a statistical model to measure temperature, $\mathrm{pH}$, and level. The present study also found that the operational parameters analyzed showed variability with its consequent effect on the quality of the final product. The findings of this study should serve as the first step towards any future research and development that may take place in the field of agro-industrial process design.

Keywords:

Sensor; Microcontroller; Temperature--pH modeling; Quality attributes.

\footnotetext{
Magíster en automatización y sistemas de control, profesor-Instituto Superior Tecnológico Francisco de, Pastaza-Ecuador. Contacto: octavio.guijarro@itsfo.edu.ec

"** Magíster en matemáticas, profesor-Universidad Estatal Amazónica, Pastaza-Ecuador. Contacto: vcerda@uea.edu.ec

**** Doctor en ciencias técnicas, profesor-Universidad de Camagüey Ignacio Agramonte Loynaz, Camagüey -Cuba. Contacto: isnel.benites@reduc.edu.cu

***** Máster of Science en Nanociencia y Nanotecnología, profesor-Universidad Regional Amazónica, Napo-Ecuador. Contacto: galo.cerda@ikiam.edu.ec

***** Doctora en ciencia y tecnología química, profesor-Universidad Estatal Amazónica, Pastaza-Ecuador. Contacto: e.guardadoy@uea.edu.ec

${ }^{* * * * * * * *}$ Magíster en gestión de bases de datos, profesor-Universidad Estatal Amazónica, Pastaza-Ecuador. Contacto: bortega@uea.edu.ec

******** Doctor of Science, profesor emérito Universidad Central "Martha Abreu” de las Villas, Santa Clara-Cuba. Contacto: erenio@uclv.edu.cu

******** Doctor en ciencias técnicas, profesor-Universidad Estatal Amazónica, Pastaza-Ecuador. Contacto: amperez@uea.edu.ec
} 


\section{Resumen:}

Se implementó un sistema local de adquisición, procesamiento y almacenamiento de datos mediante una tarjeta microcontrolada de código abierto. Para registrar continuamente las variables del proceso de producción de la miel de caña se utilizó cinco sensores de temperatura, un sensor de $\mathrm{pH}$ y un sensor de nivel. Cada sensor se asoció con un conjunto de componentes con sus respectivos valores de referencia superior e inferior durante el procesamiento de un lote de producto. El objetivo principal fue determinar la efectividad del uso de sensores y tecnologías de comunicación inalámbrica para monitorear los parámetros operacionales en tiempo real. En general, los datos de temperatura, $\mathrm{pH}$ y nivel registrados por los sensores correspondían estrechamente a los cambios que ocurrieron en el proceso, y los nodos de comunicación inalámbrica desarrollados midieron y monitorearon con éxito las lecturas de temperatura, $\mathrm{pH}$ y nivel en tiempo real. El estudio también encontró que las lecturas de temperatura, $\mathrm{pH}$ y nivel obtenidas por los sensores comenzaron a estandarizarse dentro de los límites superior e inferior. Además, los parámetros operacionales podrían predecirse razonablemente aplicando un modelo estadístico para medir la temperatura, el $\mathrm{pH}$ y el nivel. Los parámetros operacionales analizados mostraron variabilidad con su consecuente efecto sobre la calidad del producto final. Los hallazgos de este estudio deberían servir como el primer paso para el desarrollo futuro en el campo del diseño de procesos agroindustriales.

\section{Palabras clave:}

Sensor; Microcontrolador; Modelado de temperatura y pH; Atributos de calidad. 


\section{INTRODUCTION}

An emerging class of industrial production systems is called the Industrial Internet of Things (IoT) which, when successfully adopted, provides high efficiency and cost benefits for installation, maintainability, reliability, scalability, and interoperability [1]. Remote monitoring systems via the Internet allow information about a remote process to be viewed in real-time, which can be applied at an industrial level by small and medium-sized companies (PYMES) [2]. Although loT applications are still in the early stages, several major industries have implemented them in environmental monitoring, healthcare service, inventory management and production, logistics, and supply chain systems [3]. The critical component to creating loT systems is communication technologies, which allow all devices and machines to connect, communicate, and exchange data. At that time, the system can monitor, collect, exchange, and analyze data, delivering valuable services that, in turn, allow companies in the industry to make more accurate and faster decisions that help reduce their uncertainty [4].

Data Acquisition Systems (DAQ) allow information collection to be processed, analyzed, and documented [5]. This process has been simplified and made more accurate, versatile, and reliable due to the use of sensors [6], [7].

The transformation of traditional processes and machinery for digitization involves many risk factors such as volatility, ambiguity, complexity, and uncertainty. An effective way to manage these factors is by integrating machine learning techniques in Industry 4.0 applications [8]. Using Industry 4.0 in various industrial functions and applications can help channel resources and performance improvement efforts to meet quality requirements to maximize profits through productivity improvements [1]. Monitoring systems are often employed to provide diagnostic monitoring that collects relevant trend and fault data used for diagnostic trends requiring technology monitoring [9].
In the case of agribusiness, the context is no different as these systems are used to monitor and control processes [10] remotely. In particular, the minimally processed derivatives of sugar cane (DMPC) are artisanal processes with technological problems that affect quality [11], [12].

The variability of the operational parameters affects the number of defective products [13], [14].

However, studies that allow real-time monitoring of agro-industrial processes and their variables as design parameters are limited [15].

Therefore, this study aims to present a contribution to fill this gap and investigate the use of information systems in the cloud for process design. The main objective of this document is to show the monitoring of disturbances of an agro-industrial process. For this purpose, a remote monitoring system via the Internet of the honey production process is proposed. To achieve the objective of this document, the behavior of the variables level, $\mathrm{pH}$, and temperature was experimentally investigated in an artisan factory.

\section{MATERIALS AND METHODS}

The process of data acquisition, processing, and local storage is carried out through an open-source microcontrolled development board. The development of the instrumentation system involved the use of electronic elements, sensors, low-cost embedded systems, and open source software to make it an affordable system.

The sugar cane honey production process variables were acquired using five temperature sensors, a $\mathrm{pH}$ sensor, and a level sensor connected to an open-source micro-controlled card. The information obtained is stored locally in a solid-state memory and sent via a Wi-Fi device to a remote database to be processed, stored, and dynamically displayed. 


\section{Data acquisition system}

The data acquisition system developed (see figure 1 ) is based on the use of a micro-controlled electronic platform under a Creative Commons license, while the programming software is of the General Public License (GPL) type [16]. The executed project meets the following characteristics: low-cost elements, multiplatform software, simple and straightforward programming environment, open-source and extensible programming software, and hardware scalability.

The data acquisition process, processing, and storage are carried out through a micro-controlled development card where the main element is an ATmega2560 microcontroller. This microcontroller has 54 General Purpose Input / Output (GPIO), of which 15 can be used as Pulse-Width Modulation (PWM) outputs, 4 Universal Asynchronous Receiver-Transmitter (UART's), 16 Analog-to-Digital Conversion (ADC).

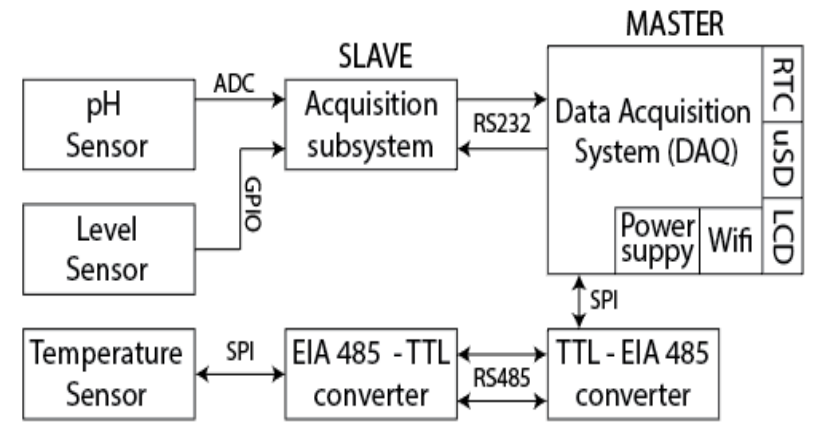

Fig. 1. Data acquisition system

The data acquisition system acquires and processes the variables from the sensors. These are visualized on a Liquid Crystal Display (LCD), and wireless communication is carried out by Transmission Control Protocol / Internet Protocol (TCP / IP) by means of the ESP8266 Wi-Fi chip. The DAQ uses the Hypertext Transfer Protocol (HTTP) to transfer the information to the webserver. A Real-Time Clock (RTC) allows the synchronization of data that is stored locally in a removable Solid-State Drive (SSD), and the stored data will be used to obtain the transfer function of the plant using parametric data identification [17], [18].

\section{Temperature data acquisition subsystem}

Acquisition of system temperatures was carried out by using K-type thermocouples, where the coming signal is compensated and digitized utilizing the MAX6675 integrated circuit. Data is transmitted to the master device using the Serial Peripheral Interface (SPI) communication standard. Because SPI cannot cover long distances, the Electronic Industries Association (EIA) -485 industry-standard data transmission was performed. [19], which works in the physical layer of the Open System Interconnection (OSI) model. Because EIA-485 is a differential bus communication system, it is used to transmit information at medium speeds and reach a maximum length of 1200 meters. Figure 2 shows the SPI-EIA485 thermal sensor network.

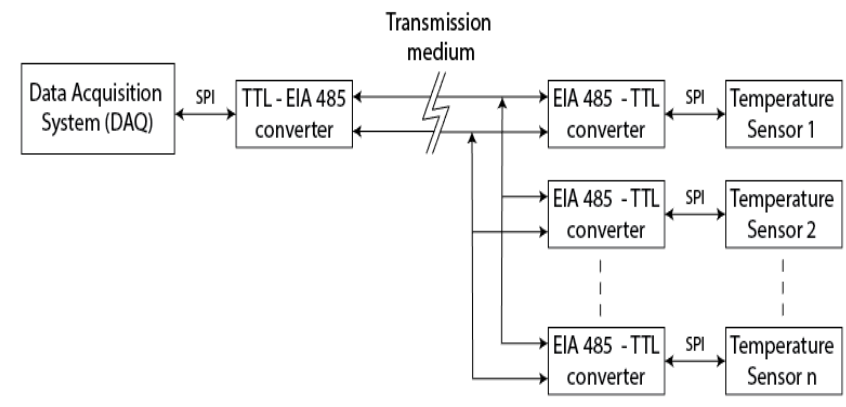

Fig. 2. SPI-EIA485 Thermal Sensor Network

The data acquisition system presents access to the medium of the master-slave type, where the data exchange is of the point-multipoint type, and the sensors occupy the medium to transmit the data only under the requirements of the data acquisition system. Table 1 shows the temperature sensor communication frame.

Table 1. Temperature sensors communication frame

\begin{tabular}{ccccc}
\hline $\begin{array}{c}\text { Dummy } \\
\text { sign bit }\end{array}$ & $\begin{array}{c}\text { 12 Bit - Temperature } \\
\text { reading }\end{array}$ & $\begin{array}{c}\text { Thermocuple } \\
\text { Input }\end{array}$ & $\begin{array}{c}\text { Device } \\
\text { ID }\end{array}$ & State \\
\hline 15 & $\begin{array}{c}1413121110987 \\
6543\end{array}$ & 2 & 1 & 0 \\
\hline 0 & MSB LSB & & 0 & $\begin{array}{c}\text { Three } \\
\text { State }\end{array}$ \\
\hline
\end{tabular}

The data frame is composed of 16 bits, where 12 bits express the temperature of the sensor. The Most Significant Bit (MSB) stores the sign of the temperatu- 
re, bit number two reports the status of the probe by setting a high level when the thermocouple is open (disconnected), so its standard operating value is zero, while bit one is used as a device indicator and bit zero represents the state of the data output.

\section{$\mathrm{pH}$ and level data acquisition subsystem}

The subsystem is an independent device from the main data acquisition system (master) as in figure 3, the exchange of information between these two electronic systems is carried out by request of the master using the EIA / TIA RS232 communication standard [18], [20].

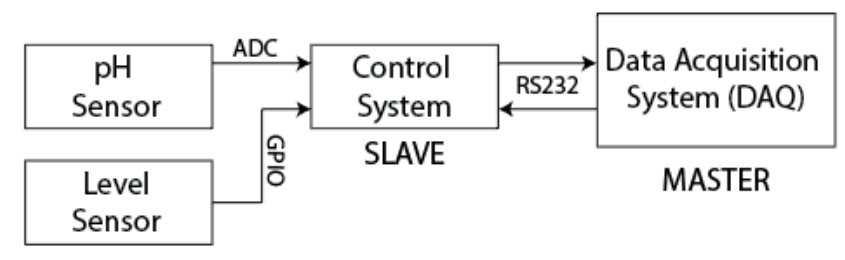

Fig. 3. RS-232 Master-Slave communication

The $\mathrm{pH}$ sensor measures the degree of acidity value of the solution to be processed in a range from 0 to 14 . This sensor emits an electrical voltage that varies over time depending on the $\mathrm{pH}$ value, which is determined based on Equation 1.

$$
\mathrm{pH}=[-15.17 / 184(\mathrm{ADC}-930)]
$$

Where: $\mathrm{pH}$ : It is the $\mathrm{pH}$ value present in the fluid, $A D C$ is the digitized value in 10 bits format of the voltage delivered by the $\mathrm{pH}$ sensor conditioner.

The ultrasound liquid level sensor measures the distance in meters between the sensor and the liquid. This is installed at a height " $\mathrm{h}$ " from the base of the container, " $u$ " is the distance measured by the sensor towards the liquid which is variable in time and depends on the flow of raw material from the extraction stage of cane juice (see figure 4).

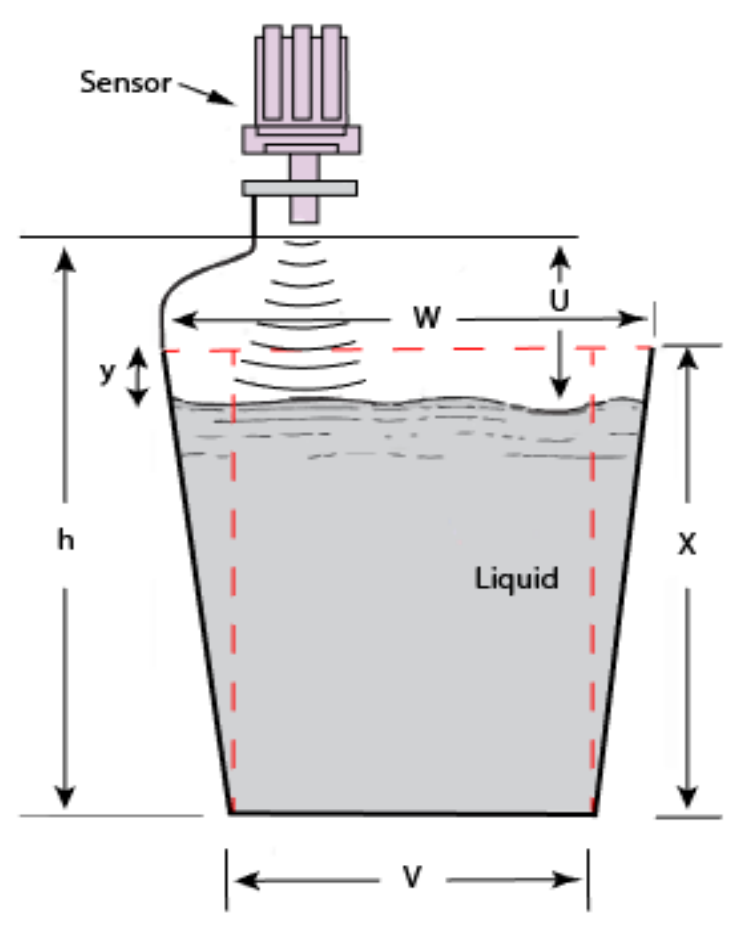

Fig. 4. Calculation of liquid volume

Applying Equation 2 and 3, the volume of the liquid present in the container in a finite time is determined.

$$
\begin{aligned}
& V_{\Delta t}=[(h-u) z \cdot w] \\
& V_{1}=1000 V_{\Delta t}
\end{aligned}
$$

Where: $\mathrm{V}_{\Delta \mathrm{t}}$ : volume of measured liquid, $\mathrm{m}^{3}, \mathrm{~V}_{\mathrm{l}}$ : liquid volume, $\mathrm{L}, \mathrm{z}$ : container length, $\mathrm{m}$.

The data acquisition system (master) requests the status of the sensors to the acquisition subsystem (slave) and the data frame emitted by the slave encapsulates the data from the $\mathrm{pH}$ sensor, liquid level sensor, and volume calculation. Table 2 shows the RS-232 SlaveMaster data frame. 
Table 2. Data frame RS-232 Slave - Master

\begin{tabular}{rrrrrrrrr} 
& pH Data & & Divider & & Distance & & Divider & \multicolumn{2}{c}{ Volume } \\
Int & Dec & $:$ & & Int & Dec & $:$ & Int & Dec \\
\hline
\end{tabular}

Where: $\mathrm{pH}$ data: $\mathrm{pH}$ value present in the sensor probe, Divisor: fixed character (that separates the data from the plot). Distance: data delivered by level sensor (m).

Volume: volume of raw material presents in the stage $\left(\mathrm{m}^{3}\right)$. Int: data integer value, Dec: decimal value of the data ( 2 decimals).

\section{Online variable writing and transmission}

The variables coming from the different sensors are stored in a web server using a web client embedded in the open-source development card used for the data acquisition system. Access to the Wireless Local Area Network (WLAN) is done through the WI-FI Node MCU ESP12E module (figure 5).

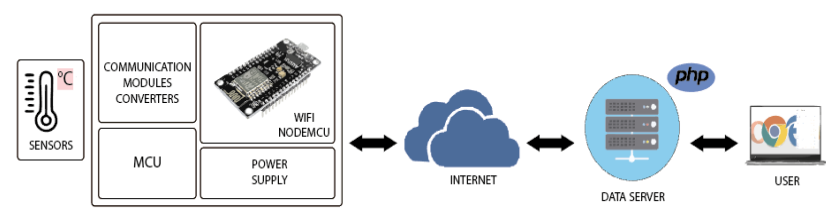

Fig. 5. Data acquisition, storage, and visualization system using a web application

Through a websocket, the web client stores the variables of $\mathrm{pH}$, liquid volume, and temperatures of the Heating stage, Evaporator 1, Evaporator 2, Evaporator 3 , Concentrator, acquired and processed in real-time by the data acquisition system [15], [21].

The communication protocol for exchanging information between the server-client is TCP, which is a connection-oriented protocol. End-users have access to the client part of the application, which builds a request for said service, then sent to the application server through the TCP / IP protocol as transport. The passed variable values were stored directly to a MySQL database using writable user credentials. A server developed in Nodejs was configured, with a MySql library configuration and a polling interval of five milliseconds, which kept listening for connections through websockets. A websocket client based on Angular 5 and ng2-charts display library was developed that received the changes issued by the server and graphs them in real-time. Each sensor was associated with a component set with its respective upper and lower reference values, represented with blue and red lines, respectively

\section{Operational parameters as design variables}

To validate the proposed system, the temperature is considered in the heating operations, evaporation 1,2 , 3; for this, 809 temperature measurements are taken in each piece of equipment. In the same way, level and $\mathrm{pH}$ measurements are taken for a total of 359 measurements. Descriptive statistics are performed on the recorded data, and the interrelationships between the variables are described to evaluate their influence.

\section{Local display of variables}

The operators can visualize the various data generated in the agro-industrial process through an LCD, which allows representing a total of 80 American Standard Code for Information Interchange (ASCII) distributed in 4 lines (see figure 6).

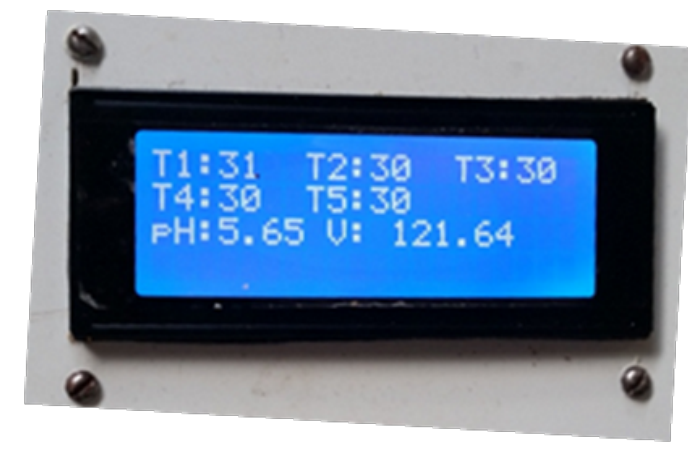

Fig. 6. Local display of variables 
Where: $\mathrm{T} 1$ : Temperature of the Heating stage, $\left({ }^{\circ} \mathrm{C}\right)$, T2: Temperature of the Concentration stage, $\left({ }^{\circ} \mathrm{C}\right), \mathrm{T} 3$ : Temperature of the third Evaporation stage, $\left({ }^{\circ} \mathrm{C}\right), \mathrm{T} 4$ : Temperature of the second evaporation stage, $\left({ }^{\circ} \mathrm{C}\right), \mathrm{T}$ : Temperature of the first Evaporation stage, $\left({ }^{\circ} \mathrm{C}\right), \mathrm{pH}: \mathrm{pH}$ value of the heating stage, $\mathrm{V}$ : Volume of cane juice present in the Heating stage, $\left(\mathrm{m}^{3}\right)$.

\section{RESULTS AND DISCUSSION}

\section{Monitoring and data acquisition system}

Through the various tests of the system, approximately 809 temperature and 359 level and $\mathrm{pH}$ records were collected. The data generated in the production process is stored in a web server and in a data logger housed within the acquisition system. This information can be accessed quickly and structured to be analyzed and processed to propose control systems.

The implemented data acquisition system can be installed anywhere that has or does not have an internet connection. This connection allows to record the variables of the sensors in a database; if there is no such connection, the variables will be stored only in the datalogger.

The system initially supports $8 \mathrm{SPI}$ sensors and can be scaled up to 256 , primarily limited by the hardware digital output ports. The data acquisition system prototype was built using open-source microcontroller hardware, publicly licensed software, and low-cost electronic devices.

\section{Writing and transmission of variables online}

Figure 7 shows the temperature values of the heater and the three evaporators. These results show the variability in the heater and the three evaporators.
In the case of evaporator 3 the temperature gradually rises to a value where it drops sharply by about 10 ${ }^{\circ} \mathrm{C}$. Later this cycle is maintained in time. In the case of evaporators 2 and 3 , there is a tendency to remain constant around their average value, not the behavior for the concentrator, which tends to increase.

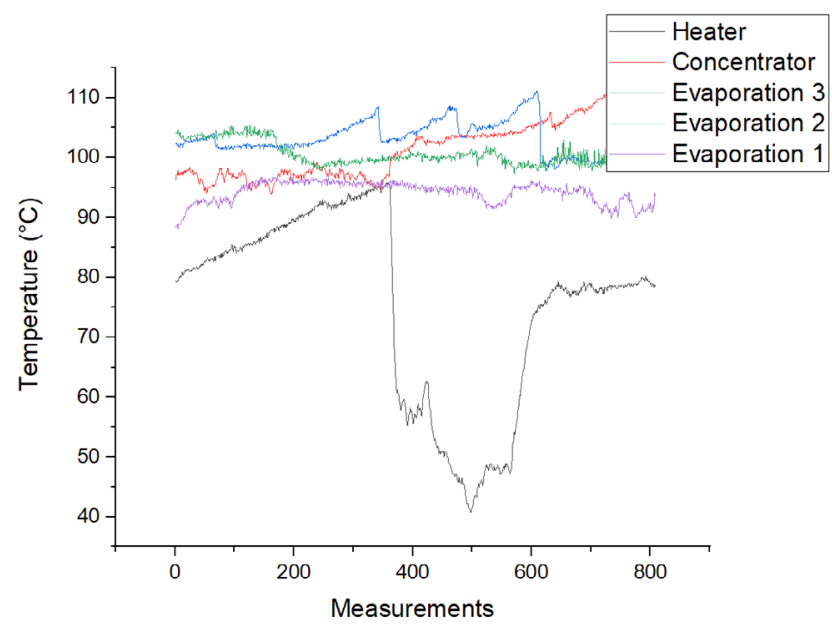

Fig. 7. Behavior of temperatures

In the heater's case, there is an increase of about $20{ }^{\circ} \mathrm{C}$ in the first 350 measurements corresponding to a time of $0.33 \mathrm{H}$. From this moment on, it drops sharply around $40{ }^{\circ} \mathrm{C}$ due to the transition between batches. It continues with a gradual decrease in about 200 measurements equivalent to a time of $0.22 \mathrm{H}$, from where it begins to increase to about $80^{\circ} \mathrm{C}$ and becomes constant around $80^{\circ} \mathrm{C}$. This behavior occurs because another batch is started during this period.

Table 3. Models that relate the different temperatures of the process

\begin{tabular}{cc}
\multicolumn{1}{c}{ Model } & $\mathbf{R}^{2}$ \\
\hline $\mathrm{T}_{\text {ev2 }}=-0.269 \mathrm{~T}_{\text {evap } 1}+125.9$ & 0.061 \\
\hline $\mathrm{T}_{\text {ev3 }}=-0.253 \mathrm{~T}_{\text {evap } 2}+128.5$ & 0.028 \\
\hline $\mathrm{T}_{\text {conc }}=-0.398 \mathrm{~T}_{\text {evap } 3}+1414$ & 0.058 \\
\hline $\mathrm{T}_{\text {ev1 }}=0.020 \mathrm{~T}_{\text {calent }}+92.71$ & 0.032 \\
\hline
\end{tabular}

Table 3 shows the models that characterize these relationships. The absence of favorable $R^{2}$ values indicates a significant variability in the data and that there are other variables affecting heat transfer with its consequent effect on the quality of the final product. 
However, these models serve the producers to predict the levels at which the temperatures of the different equipment should be worked; thus, they constitute an indispensable tool for carrying out the mass and energy balances of the process and optimizing energy consumption.

Figure 8 shows the $\mathrm{pH}$ behavior. It is appreciated that being an artisan process, there is no $\mathrm{pH}$ control since the liming method is empirical, coinciding with that reported by Guerra and Mujica [22]. However, this variability of the operating parameter affects, according to Cerda [23], the quality of the final product.

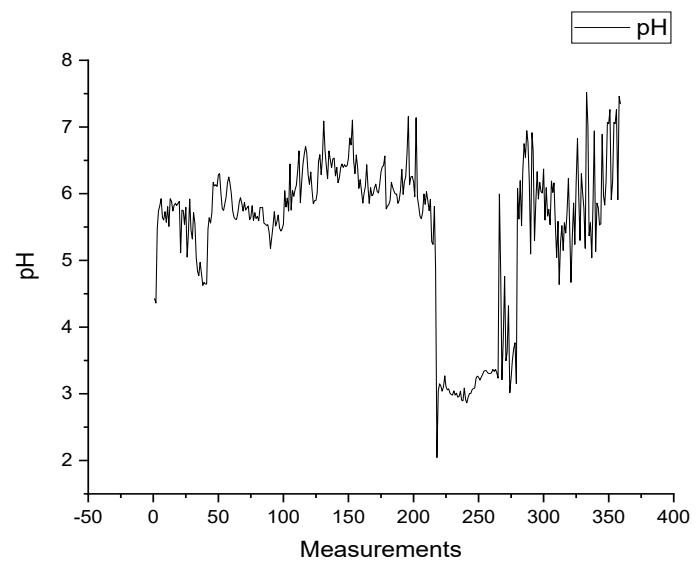

Fig. 8. pH behavior

The level behavior is presented in figure 9. The results show the level increase at the beginning of each production batch according to the grinding capacity and the reduction of the level as the honey is concentrated.

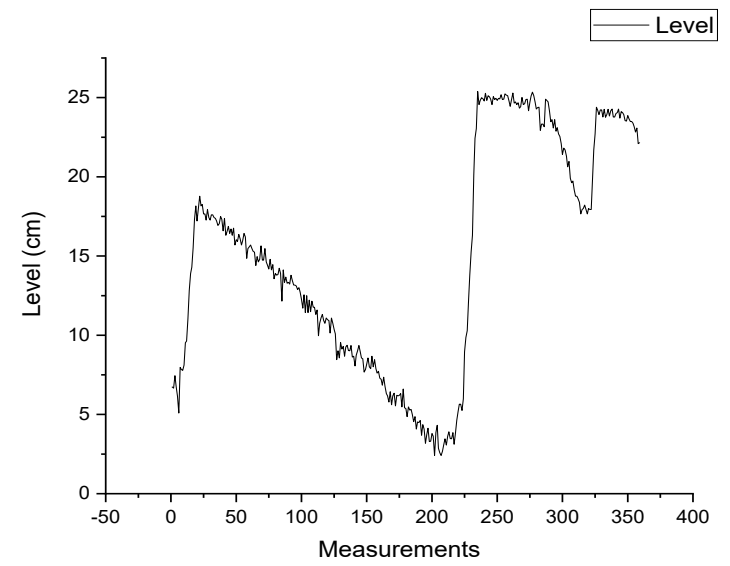

Fig. 9. Level behavior (cm)

\section{Operational parameters as design variables}

Table 4 shows the descriptive statistics of the measurements of temperature, $\mathrm{pH}$, and level of the discontinuous process of cane honey production; the results shown are indicators of this work regime.

Table 4. Descriptive statistics of the operating parameters

\begin{tabular}{|c|c|c|c|c|c|c|c|}
\hline & $\begin{array}{l}T_{\text {heating }} \\
\left({ }^{\circ} \mathrm{C}\right)\end{array}$ & $\begin{array}{l}\mathrm{T}_{\text {concentration }} \\
\left({ }^{\circ} \mathrm{C}\right)\end{array}$ & $\begin{array}{l}\mathrm{T}_{\text {evaporation }} \\
{ }_{3}\left({ }^{\circ} \mathrm{C}\right)\end{array}$ & $\begin{array}{l}T_{\text {evaporation }} \\
{ }_{2}\left({ }^{\circ} \mathrm{C}\right)\end{array}$ & $\begin{array}{l}\mathrm{T}_{\text {evaporation }} \\
\left({ }^{\circ} \mathrm{C}\right)\end{array}$ & $\mathrm{pH}$ & $\begin{array}{l}\text { Level } \\
(\mathrm{m})\end{array}$ \\
\hline Minimum & 40.7 & 103.7 & 105.5 & 101.5 & 94.5 & 4.36 & 0.0637 \\
\hline Maximum & 95,7 & 97 & 102.7 & 100 & 95 & 7.3 & 0.221 \\
\hline Difference & 55 & 6.7 & 2.8 & 1.5 & 0.5 & 2.99 & 0.157 \\
\hline Average & 75.3 & 101.3 & 103.0 & 100.5 & 94.2 & 5.4 & 0.151 \\
\hline S.D & 15.7 & 4.66 & 2.9 & 2.13 & 1.77 & 1.14 & 7.2 \\
\hline CV & 20.9 & 4.6 & 2.8 & 2.1 & 1.9 & 20.8 & 48.4 \\
\hline
\end{tabular}

In the case of the heater temperature, there is a difference of more than $50{ }^{\circ} \mathrm{C}$ between the minimum and maximum recorded values, expressed in a standard deviation of $15.7^{\circ} \mathrm{C}$ and a coefficient of variation greater than $10 \%(20.9 \%)$. In the following operations, the temperature shows minimal standard deviation levels and coefficients of variation, indicating that there is very little variability of this parameter. Therefore, for the realization of the mass and energy balances in these equipment's it is possible to work with the average value of the same.

In the case of $\mathrm{pH}$, a difference of 2.99 is appreciated. The variability of this operating parameter impacts the quality of cane honey, as reported by Cerda [23]. These differences may be because most sugar mills do not control acidity; it is carried out empirically, according to Mosquera, Carrera, and Villada [24]. On the other hand, it also implies the need to control the process since the optimum $\mathrm{pH}$ of the cane juice to obtain a good quality product must be between 5.6 and 5.8 , to avoid the formation of reducing sugars and favor clarification, since it facilitates the rejected according to Mujica, Guerra, and Soto [25].

For its part, the level shows great variability because part of the filling and emptying processes of the equipment is considered in the measurements. Also, to eva- 
luate a data set of batch processes obtained from an artisan factory is studied, this coincides with the statement of Shen et al. [26] that batch processes are characterized by stochastic disturbances, making monitoring of batch processes a complex problem in practice.

\section{Local display of variables}

Figure 10 shows the remote monitoring systems via the Internet that allow viewing the information on the honey production process in the "El Valle" artisan factory remotely in real-time. It is observed that the operating parameters are controlled.

Each sensor is configured with independent maximum and minimum values, and this monitoring reduces the variability of the operational parameters. According to Cerda [23] has a positive impact on the quality of the final product.

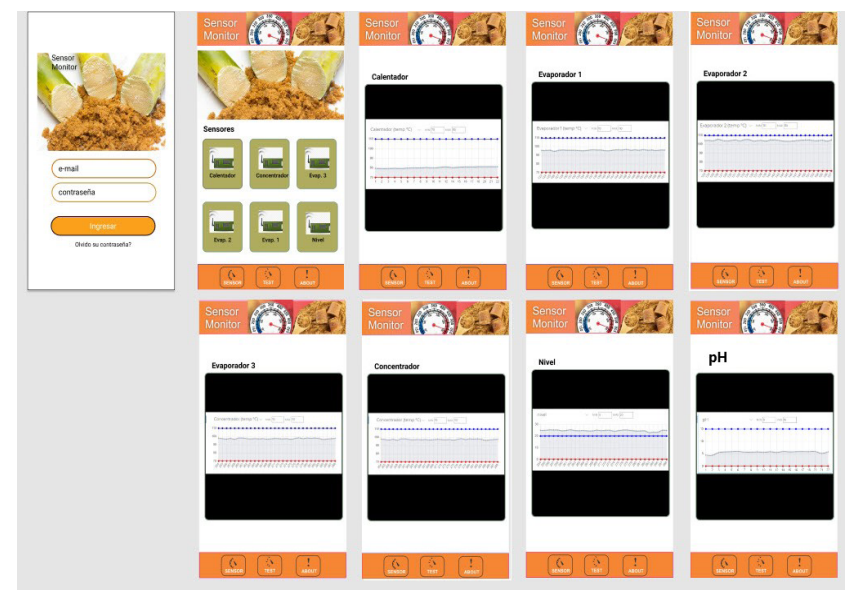

Fig. 10. Real-time graph of the temperature in the heater, evaporators $1,2,3$, concentrator, level, and $\mathrm{pH}$

\section{CONCLUSIONS}

Implementing a Data Acquisition System with Real Time Web Visualization of the variables of the cane honey production process is relevant to pass an artisan production to semi-industrial. The case of temperature, $\mathrm{pH}$, and level measurements allows the operator to know the system's behavior during its various stages of development at different stages of the process. Its correlation analysis allows establishing the mathematical relationship between them, resulting in an essential tool for the subsequent performance of mass and energy balances as a basis for the design of processes.

The differences between the values of the different operating parameters are since the production process is discontinuous and artisanal, with higher levels of variability in $\mathrm{pH}$ and the temperature of the heating stage. This work allowed to take the first step to control the quality of the cane honey production process and implement the Internet of Things in the artisan production of Ecuador.

\section{ACKNOWLEDGMENT}

The authors thank: Universidad Estatal Amazónica, Instituto Superior Tecnológico Francisco de Orellana, Universidad de Camagüey Ignacio Agramonte Loynaz y Universidad Central "Martha Abreu" de las Villas, for having facilitated the development of this research.

\section{REFERENCES}

[1]. D. S. Kim and H. T. Dang, Industrial Sensors and Controls in Communication Networks From Wired Technologies to Cloud Computing and the Internet of Things. Switzerland: Springer, 2019.

[2]. S. Escudero, M. Merino, and R. Vásquez, "Sistema de monitoreo remoto vía internet con generación de indicadores de producción para procesos automatizados," Revista Politécnica, vol. 10, no. 19, pp. 35-45, 2014. Disponible en https://revistas. elpoli.edu.co/index.php/pol/article/view/470

[3]. M. Barrio, Internet de las cosas, Primera. Madrid: REUS, 2018. 
[4]. M. Tascón and C. Arantza, Big Data y el Internet de las cosas: Qué hay detrás y cómo nos va a cambiar, Primera. Madrid, 2016.

[5]. M. Azúa-Barrón, M. A. Vázquez-Peña, R. ArteagaRamírez, and R. Hernández-Saucedo, "Sistema de adquisición de datos de bajo costo con la plataforma arduino", Revista Mexicana de Ciencias Agrícolas, vol. 8, no. 1, pp. 1-12, 2017. https:// doi.org/10.29312/remexca.v8i1.67

[6]. A. 0. Chase, M. H. K. Sampaio, J. R. Brito-De-Souza, and J. F. Almeida, “Data acquisition system: An approach to the Amazonian environment", IEEE Latin America Transactions, vol. 10, no. 2, 2012. https://doi.org/10.1109/TLA.2012.6187606

[7]. F. Pethig, B. Kroll, 0. Niggemann, A. Maier, T. Tack, and M. Maag, "A generic synchronized data acquisition solution for distributed automation systems", in IEEE International Conference on Emerging Technologies and Factory Automation, ETFA, 2012.

[8]. B. Mohanta, P. Nanda, and S. Patnaik, New Paradigm of Industry 4.0: Internet of Things, Big Data \& Cyber Physical Systems. Switzerland: Springer, 2020.

[9]. S. Hunt, "Data acquisition unit for remote monitoring system and method for remote monitoring", US 6,556,956 B1, 2003.

[10]. J. Poma Deza, R. Tello Yuen, and E. Ruiz Lizama, "Diseño de una estación virtual para el control de las perturbaciones que afectan la temperatura de los procesos industriales", Industrial Data, vol. 10, no. 1, pp. 33-41, 2007. https://doi. org/10.15381/idata.v10i1.6214

[11]. J. Espitia, F. Velásquez, R. López, S. Escobar, and J. Rodríguez, "An engineering approach to design a non-centrifugal cane sugar production module:
A heat transfer study to improve the energy use", Journal of Food Engineering, vol. 274, 2020. https://doi.org/10.1016/j.jfoodeng.2019.109843

[12]. F. Velásquez, J. Espitia, 0. Mendieta, S. Escobar, and J. Rodríguez, "Non-centrifugal cane sugar processing: A review on recent advances and the influence of process variables on qualities attributes of final products", Journal of Food Engineering, vol. 255, no. February, pp. 32-40, 2019. https://doi.org/10.1016/j.jfoodeng.2019.03.009

[13]. V. R. Cerda Mejía, A. Pérez-Martínez, E. GonzálezSuárez, and D. Concepción Toledo, "El diseño de procesos bajo condiciones de incertidumbre: estrategia para el desarrollo socio-económico en la agroindustria ecuatoriana", Revista Universidad y Sociedad, vol. 11, no. 5, pp. 131-139, 2019.

[14]. V. R. Cerda Mejía, A. Pérez-Martínez, and E. Gonzales Suarez, "Procedimiento para el diseño óptimo de procesos considerando la calidad: aplicación en la elaboración de miel de caña", Centro Azúcar, vol. 47, no. 4, pp. 103-113, 2020.

[15]. B. Ortega-Tenezaca, V. Quevedo-Tumailli, V. R. Cerda Mejía, 0. Guijarro Rubí, E. Guardado Yordi, and A. Pérez-Martínez, "Web Application for Real Time Data Visualization of Heat Sensor", in Proceedings of MOL2NET 2018, International Conference on Multidisciplinary Sciences, 4th edition, 2018, p. 5909.

[16]. M. Meda, "Licenses of open source software and their economic values, in Proceedings-2005 Symposium on Applications and the Internet Workshops, SAINT2005, 2005, vol. 2005, pp. 381-383.

[17]. V. Aparna, “Development of automated pH monitoring and control system through USB Data Acquisition", in Proceedings of 6th IEEE Power India International Conference, PIICON 2014, 2014. 
[18]. S. Wali and M. Areeb, “Development of Low-Cost DAQ for Power System Signals Using Arduino", in Proceedings of the 21st International Multi Topic Conference, INMIC 2018, 2018.

[19]. X. Li, B. Zhang, F. Zhong, and X. G. Liu, "Research and implementation of the temperature control system of heat treatment based on .net and RS485 bus", in Proceedings-2010 International Conference on Intelligent Computing and Integrated Systems, ICISS2010, 2010, pp. 341-345.

[20]. Z. A. M. Almaqtari and Z. Janin, “Development of virtual pH analyzer", in 2013 IEEE International Conference on Smart Instrumentation, Measurement and Applications, ICSIMA 2013, 2013. 10.1109/ICSIMA.2013.6717976

[21]. I. Fette, A. Melnikov, and I. Ltd., "The WebSocket Protocol", Internet Engineering Task Force, 2011. [Online]. Available: https://tools.ietf.org/ pdf/rfc6455.pdf. [Accessed: 10-Jun-2020].

[22]. M. Guerra and M. Mujica, "Physical and chemical properties of granulated cane sugar "panelas", Ciência e Tecnologia de Alimentos, vol. 20, no. 1, 2009.
[23]. V. R. Cerda Mejía et al., "Influence of the uncertainty of the operational parameters in obtaining cane syrup in sensorial attributes", in Proceedings of MOL2NET 2016, International Conference on Multidisciplinary Sciences, 2nd edition, 2016, p. 3897.

[24]. S. Mosquera Sánchez, J. Carrera, and H. Villada Castillo, "Variables que afectan la calidad de la panela procesada en el Departamento del Cauca", Biotecnol. en el Sect. Agropecu. y agroindustrial, vol. 5, no. 1, pp. 17-27, 2007. Disponible en: https://revistas.unicauca.edu.co/index. php/biotecnologia/article/view/645/276

[25]. M. V. Mujica, M. Guerra, and N. Soto, "Efecto de la variedad, lavado de la caña y temperatura de punteo sobre la calidad de la panela granulada", Interciencia, vol. 33, no. 8, pp. 598-603, 2008.

[26]. Y. Shen, X. D. Steven, A. H. A. Sari, and H. Hao, "Data-driven monitoring for stochastic systems and its application on batch process", International Journal of Systems Science, vol. 44, no. 7, pp. 1366-1376, 2013. https://doi.org/10.1080/0020 7721.2012 .659708 